\title{
Histopathology Description of Chicken Liver Infected by L2 Toxocara Vitulorum
}

\author{
Rizkiyatu Auliyah ${ }^{1}$, Kusnoto $^{1 *}$ and Iwan Sahrial Hamid ${ }^{2}$ \\ ${ }^{I}$ Department of Veterinary Parasitology, Faculty of Veterinary Medicine, Universitas Airlangga, Surabaya, 60115, Indonesia \\ ${ }^{2}$ Department of Veterinary Basic Medicine, Faculty of Veterinary Medicine, Universitas Airlangga, Surabaya, 60115, Indonesia \\ *Corresponding author’s Email: kk.kusnoto@yahoo.com; ORCID: 0000-0003-3915-654X
}

Received: 21 Jan. 2021

Accepted: 10 Mar. 2021

\begin{abstract}
Transmission of Toxocara vitulorum Infection causes a decrease in livestock productivity and results in various types of diseases in humans. Chickens are one of the parasitic hosts of toxocariasis which has the potential for transmission of toxocariasis to humans. The main location affected by $T$. vitulorum larval infection is the liver. The current study aimed to analyze the description of histopathological changes in the liver of broiler chickens infected by L2 Toxocara vitulorum. The present study was a true experiment using a completely randomized design. A total number of 28 broiler chickens aged 14 days were selected as the sample in this study. Samples were infected using L2 Toxocara vitulorum larvae and were grouped in accordance with observations of the 1,2,3,7,14, and 21 days after the larvae were given to the samples. Toxocara vitulorum larval infection caused changes in histopathological features of broilers chickens. This infection caused hydropic inflammation and degeneration of liver cells, cholangitis, and eventually necrosis of the cells. Exposure to infection over a long period of time can worsen liver cell and other organ damages as well as increasing the potential for the transmission of Toxocara vitulorum larvae.
\end{abstract}

Keywords: Chicken, Histopathology of liver, Infection, Toxocara vitulorum

\section{INTRODUCTION}

Toxocariasis is one of the worm-originating diseases that can attack ruminants, especially calves of cows and buffaloes and the mothers (Hübner et al., 2001). Toxocara vitulorum which attacks cows at all ages can be transmitted through food boxes or placenta that can infect the fetus in the womb (Levine, 1995). Toxocara vitulorum is commonly found in tropical and subtropical climates (Starke et al., 1996). This infection leads to a reduction in livestock productivity, which will be a financial burden for farmers if not controlled. In addition, $T$. vitulorum infection causes anorexia, stomach pain, diarrhea, constipation, dehydration, bad breath, and also a decrease in the body weight of cattle (Raza et al., 2013).

Humans or animals that consume raw or undercooked liver of paratenic hosts of Toxocara spp. are the potential to being contaminated with toxocariasis (Yoshikawa et al., 2008). Some paratenic hosts of toxocariasis are mice, rats, pigs, birds, chickens, humans, and other mammals (Azizi et al., 2007; Yoshikawa et al., 2008; Raza et al., 2013). Larvae can move to various tissues and survive for a long period of time (Azizi et al., 2007; Strube et al., 2013). The movement of larvae into the tissues (lung, liver, and kidney) or milk is thought to be a medium of transmission to humans (Kusnoto et al., 2005). The consumption amount of raw or undercooked meat increases the prevalence of toxocariasis cases (Taira et al., 2011) leading to human zoonosis diseases, such as visceral larva migrans (VLM) and ocular larva migrans (OLM).

T. vitulorum larvae can cause liver and lung lesions, inflammation of lymph nodes, as well as eosinophilia during the life cycle of the parasite (Abbott et al., 2006; Khan et al., 2007). Toxocara spp. larvae migrate to the liver through the porta hepatica systems and cause hepatomegaly which is a common phenomenon (Soulsby and Monnig, 1982). In humans, The human infection of Toxocara spp. leads to hepatocellular necrosis and inflammatory reactions (Hübner et al., 2001). On the other hand, histopathological examination of visceral organs using helminthiasis has not been performed much, especially to see the histopathological picture of the liver as the site of second-stage $T$. vitulorum larvae migration in 
chickens as paratenic host, where parasites can live but cannot develop into adulthood (Cardillo et al., 2008). Therefore, this study was conducted to describe the histopathological changes in the liver of broiler chickens after being infected by L2 Toxocara vitulorum.

\section{MATERIALS AND METHODS}

The present study was a true experiment using a completely randomized design performed at the Helminthology Laboratory of the Parasitology Department of Faculty of Veterinary Medicine, Universitas Airlangga, Surabaya, Indonesia, in 2020. The liver histopathology examination was carried out in the Pathology Laboratory. Three variables have been investigated in the current study. The histopathological image of the liver (degeneration and necrosis of hepatocytes) was considered as the dependent variable, the effective dose of $\mathrm{L}_{2} T$. vitulorum and liver sampling time were taken into account as independent variables. Finally, controlled variables included strain, sex, age, feed, and also environmental conditions of chickens.

\section{Experimental design}

Broiler infection involves eggs containing L2 $T$. vitulorum. Phosphate Buffer Saline (PBS) (Sigma Co.) was used as the media of L2 T. vitulorum, while the protozoa growth and other microorganisms were avoided using formalin $0.5-1 \%$. In addition, Trypsin $1 \%$ was used for releasing L2 T. vitulorum from the formed liver tissue.

\section{Isolation and preparation of Toxocara vitulorum eggs}

Infective eggs of $T$. vitulorum worm inoculant material comes from the intestine of 10 cows contaminated by toxocariasis, during visiting the slaughter-house. Worms were washed in $0.85 \%$ saline to remove debris, and they were fixed into $70 \%$ ethanol. The worms were then cleaned with aquadest and transferred to a container containing PBS solution as a development medium. After that, the worms were incubated at $37^{\circ} \mathrm{C}$ for up to three days in order to lay T. vitulorum eggs. The $T$. vitulorum egg retrieval was performed through the worm's reproductive tract by the surgical process. Subsequently, a gradient preparation technique was used to separate the dirty debris from the eggs.

\section{Toxocara vitulorum eggs fertilization}

Egg fertilization was carried out in PBS medium with the addition of five drops of formaldehyde $10 \%$. This addition served to prevent the interference of other microbes with the growth of $T$. vitulorum eggs until the first (L1) and second larvae were obtained (L2). The development of worm eggs was observed using a dissecting microscope (Olympus upright microscope) and documented in the form of photographs on a regular basis. The process took 21-28 days at room temperature until the egg developed into L2 (Kusnoto et al., 2011).

\section{Calculation of Toxocara vitulorum eggs}

The egg calculation was carried out using a modified calculation of the worm eggs per gram excretion introduced in the Lucient Brumpt method (Kusnoto et al., 2007). An amount of $1 \mathrm{ml}$ of T. vitulorum egg suspension from the culture media was then taken and diluted 10 times until $10 \mathrm{ml}$ of suspension achieved. Then, $1 \mathrm{ml}$ of suspension was taken by means of a Pasteur pipette to calculate the number of drops for every $1 \mathrm{ml}$ of suspension. One drop of the suspension was put on a glass object and then examined through a light microscope with $100 \times$ magnification. Eggs that appeared through the microscopic magnification were counted using the formula which is written below (Kusnoto et al., 2007).

Number of eggs: Number of drops per $\mathrm{ml}(\mathrm{N}) \times$ number of worm eggs per drop $(n) \times$ number of dilutions

\section{Treatment of experimental animals}

A total number of 28 broiler chickens with body weights of 100-200 gr were selected as experimental animals of the current study. The chickens were raised on the farm and the floor. The adaptation period was one week. There was no available information about the vaccination program since the study was performed during rearing. Broilers were required to be 14 days old for deviation to seven treatment groups. The chickens were quarantined (A week) before being randomly divided into seven treatments with four replications in each. The chickens were feeding ad-libitum every afternoon and morning with strict hygiene. Then, each broiler chicken was infected by using 3000 eggs containing $T$. vitulorum second stage larvae (L2) when it was added to the food. The broiler chicken groups were divided into six groups (Azizi et al., 2007; Taira et al., 2011). The broiler chickens in the control group (K) were not infected with $T$. vitulorum. The P1 consisted of broilers infected by L2 $T$. vitulorum with a dose of 3000 eggs per chicken, and euthanized a day after infection. The broilers in P2 group were infected by L2 T. vitulorum with a dose of 3000 eggs per chicken, and euthanized two days after infection. The P3 group entailed broilers infected with $\mathrm{L}_{2} T$. vitulorum with a dose of 3000 eggs per chicken, and euthanized three days after infection. The P4 had broilers infected by L2 $T$. vitulorum with a dose of 3000 eggs per chicken, and euthanized seven days after infection. Moreover, P5 was 
composed of broilers infected by L2 T. vitulorum with a dose of 3000 eggs per chicken, and euthanized 14 days after infection. Finally, the P6 group encompassed broilers infected by L2 T. vitulorum with a dose of 3000 eggs per chicken, and euthanized 21 days after infection.

\section{Liver extraction}

Liver extraction for histopathological preparation was carried out 1, 2, 3, 7, 14, and 21 days after L2 $T$. vitulorum infection. Extraction of the chicken liver was done after euthanasia and surgery. Broiler's liver organs were stored in aquadest and formalin $10 \%$. Chicken's livers were cleaned with physiological $\mathrm{NaCl}$ then put in a plastic pot containing aquadest and formalin $10 \%$, and subsequently stored for 24 hours before making the histopathological preparations.

\section{Examination of preparations}

The materials used for liver histopathological preparation were multilevel ethanol $(70 \%, 80 \%, 90 \%$, and absolute), formalin $10 \%$ added to the solution, ether, physiological saline ( $\mathrm{NaCl} 0.9 \%$ ), paraffin, entellan (transparent adhesive), Harris's Haematoxylin-Eosin double coloring, emersion oil, and xylol. Examination of preparations was performed using a light microscope with $400 \times$ magnification of five different fields of view (LP) for each sample. The observed changes included degeneration, the swelling of cell size due to vacuoles in the cytoplasm, Infiltration of inflammatory cells around the central vein, whether porta hepatis or sinusoid. Subsequent examination of preparations was assessed according to the Knodell score method (Knodell et al., 2019).

\section{Statistical analysis}

The research data including the histopathological score of liver cells of chickens were analyzed using Kruskal Wallis test, then continued with the Z-test. Differences were considered significant when $\mathrm{p}<0.05$.

\section{RESULTS AND DISCUSSION}

The present study obtained the results from the observation of isolated $T$. vitulorum worm eggs from adult worms that were fertilized and incubated for about one month. This process also obtained a second-stage larvae (L2) (Figure1). The results of the treatment on broilers microscopically demonstrated a histopathological change in the chicken liver after being infected with L2 $T$. vitulorum. Non-parametric Kruskal Wallis test indicated a significant difference $(\mathrm{p}<0.05)$ for each treatment in broilers (Table 1). Provision of infective larval infections
$\left(\mathrm{L}_{2}\right)$ T. vitulorum affects the histopathology of broiler chickens' liver. This study found a significant difference between the control group $(\mathrm{K})$ and treatment groups which were euthanized 1- 21 days post-L2 infection ( $<0.05$ ). The obtained scores were then followed by a multiple comparison test ( $\mathrm{Z}$ test) to determine the order of the change rate in the liver histopathological pictures among the seven treatment groups.

Histopathological pictures of the liver tissue in the treatment groups presented damage due to hydropic degeneration (cloudy swelling), necrosis, inflammation, and cholangitis. The $\mathrm{Z}$ test indicated significant differences in the treatment groups P1, P3, P4, P5, and P6 with the control group $(\mathrm{K})$. However, there was a change in histopathological features in $\mathrm{P} 2$ which were not significantly different from the control group. Group P6 represented the worst results, compared to other treatment groups (Figure 2).

In Figure 3, part A, hepatocytes were normal (blue sign) and did not appear to have inflammation and degeneration, and ductal images were still normal (green signs). In figure B, the cholangitis in the P6 group was characterized by inflammatory cells (yellow marking) and epithelial proliferation (red marks) of the bile duct. In figure $\mathrm{C}$, the black mark referred to the presence of hydropic degeneration, and cytoplasm appeared turbid (cloudy swelling) and the green mark referred to the necrosis of the nucleus which appeared to be picnotic. The yellow mark in figure D indicated inflammation around the portal area.

Table 1. Statistical results on the extent of liver damage to the broiler chickens infected by $T$. vitulorum

\begin{tabular}{lc}
\hline Treatment & $\begin{array}{c}\text { Liver Damage Value } \\
\left(\text { Mean Rank } \pm \mathbf{S E}^{\mathbf{1}} \text { ) }\right.\end{array}$ \\
\hline K & $2.50^{\mathrm{d}} \pm 0.289$ \\
P1 & $15.50^{\mathrm{b}} \pm 1.472$ \\
P2 & $9.63^{\mathrm{c}} \pm 0.816$ \\
P3 & $12.50^{\mathrm{bc}} \pm 1.443$ \\
P4 & $14.75^{\mathrm{b}} \pm 1.323$ \\
P5 & $21.25^{\mathrm{ab}} \pm 1.190$ \\
P6 & $25.38^{\mathrm{a}} \pm 0.645$ \\
\hline
\end{tabular}

a-d: different superscripts in the same column show significant differences $(p<0.05){ }^{1}$ SE: Standard Error. K: control group, broilers were not infected with $T$. vitulorum. P1: Broilers were infected by L2 $T$. vitulorum at a dose of 3000 eggs per chicken, and euthanized a day after infection. P2: Broilers were infected by L2 T. vitulorum at a dose of 3000 eggs per chicken, and euthanized two days after infection. P3: Broilers were infected with $\mathrm{L}_{2} T$. vitulorum at a dose of 3000 eggs per chicken, and euthanized three days after infection. P4: Broilers were infected by L2 T. vitulorum at a dose of 3000 eggs per chicken, and euthanized seven days after infection. P5: Broilers were infected by L2 T. vitulorum at a dose of 3000 eggs per chicken, and euthanized 14 days after infection. P6: Broilers were infected by L2 T. vitulorum at a dose of 3000 eggs per chicken, and euthanized 21 days after infection. 

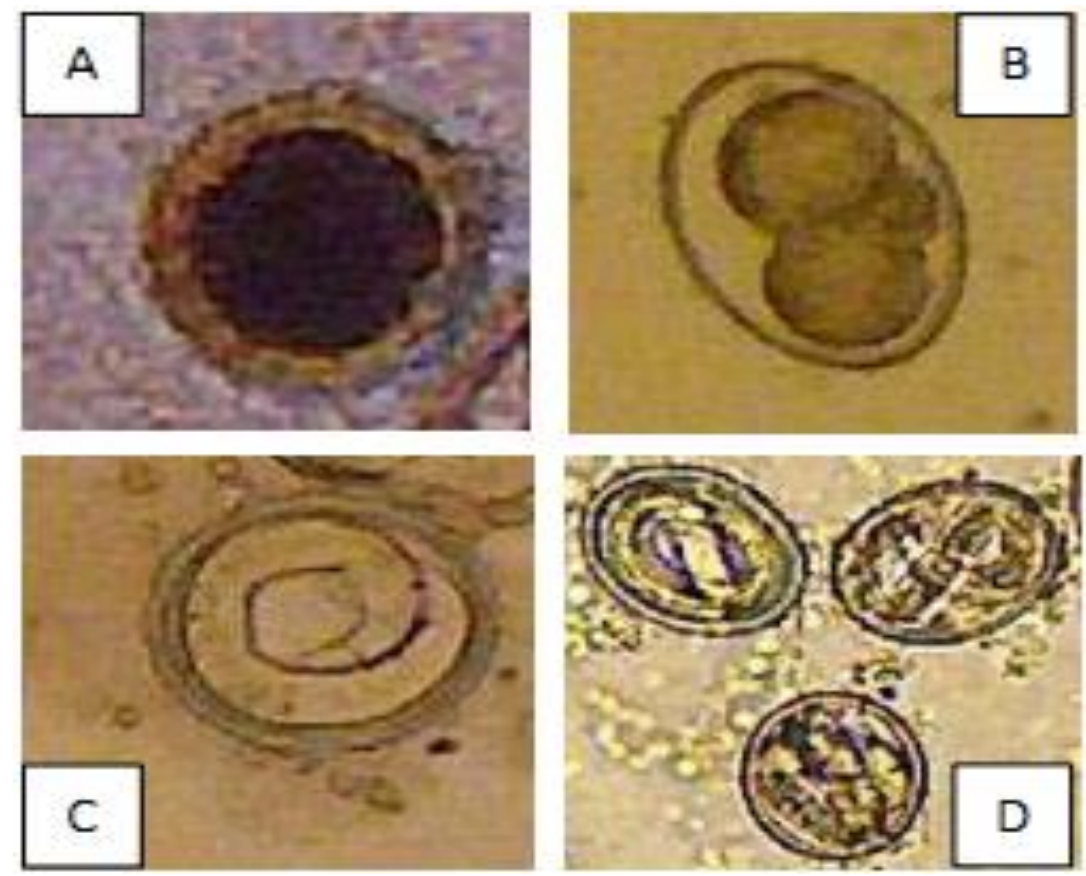

Figure 1. The results of identification of the Toxocara vitulorum worm eggs and their development up to L2 stage with $100 \times$ Magnification, A: worm eggs (1 cell), B: morula, C: L1, D: L2
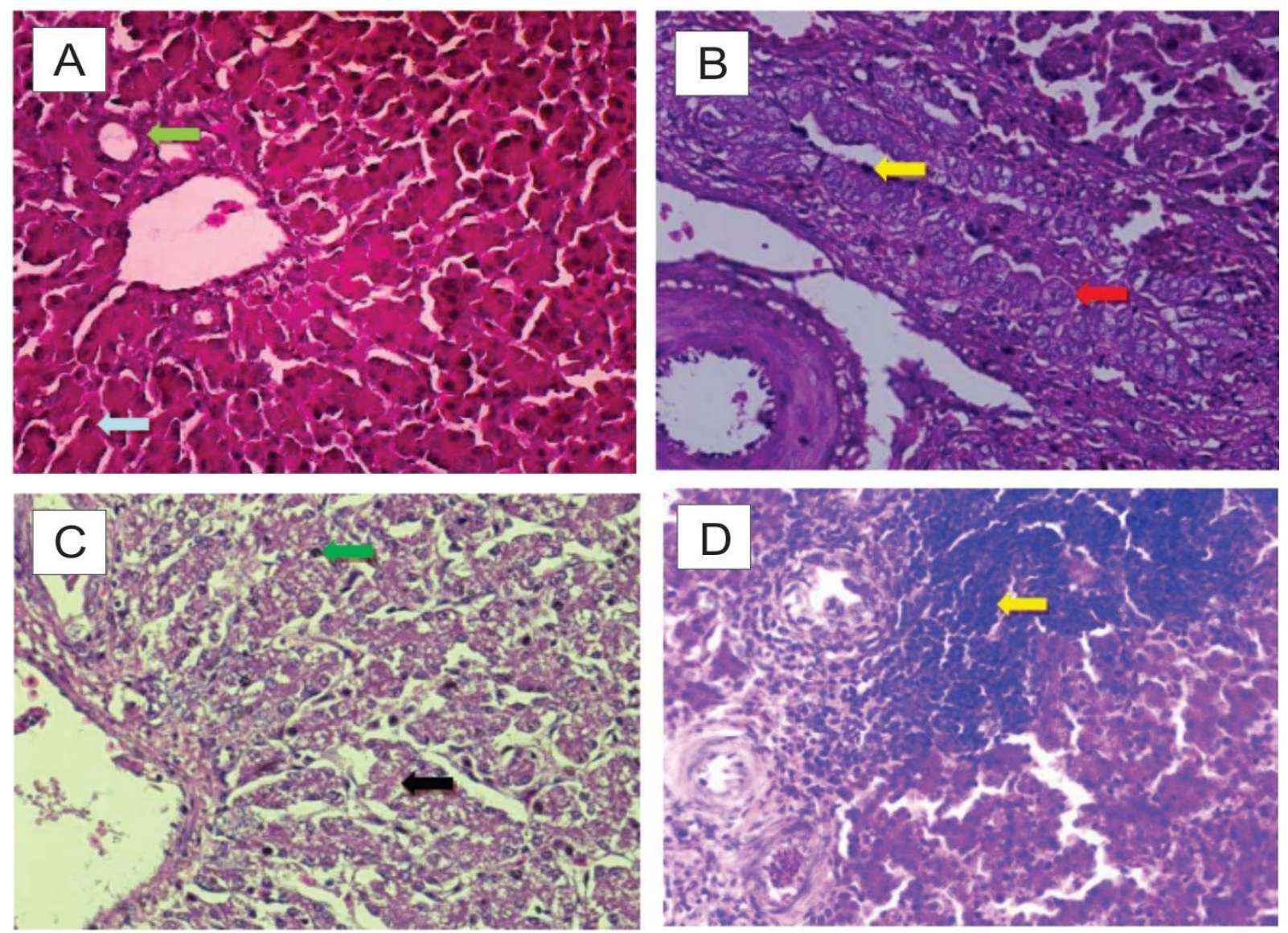

Figure 3. Histopathological picture of changes in different groups of infected broiler chickens' liver with L2 Toxocara vitulorum. Haematoxylin-Eosin coloring, 400× Zoom. A: control group; B: Chicken liver cholangitis P6, C: liver degeneration and necrosis P6, D: chicken liver inflammation P6 


\section{DISCUSSION}

The oral administration of L2 T. vitulorum caused a significant change in the liver histopathology picture of broiler chickens $(p<0.05)$. This was due to the migration of larvae into the tissue. However, the larvae were not always found on liver histopathological examination (Fenoy et al., 2001). The orally administrated 3,000 eggs presented a white spot on the hepatic surface of the chickens indicating the presence of necrotic foci, eosinophil infiltration, and some lymphocytes around the necrotic area (Azizi et al., 2007; Taira et al., 2011).

Infective eggs of $T$. vitulorum hatched within 2 hours followed by penetration into the intestinal wall to reach the liver through the porta hepatica system. The life cycle of Toxocara spp. involves a phase of migration in tissue at every stage, starting from the egg, larvae, and adult stages. Every stage of Toxocara spp. growth has different antigenic devices and immunogenicity in triggering the formation of antibodies. Infective larval migration can cause histopathological changes in the cells of organs (Santos et al., 2017).

The liver experienced severe damage in the first post-infection day with the occurrence of degeneration, necrosis, severe inflammation, and cholangitis. On the second day, the liver was damaged but there were no significant differences in histopathological features which were found between treatment groups and the control group. L2 Toxocara spp. was most commonly found in the liver on the first day after infection and L2 migrated to another site on the second day (Taira et al., 2011). On the second post-infection day, the L2 Toxocara spp. was mostly found on the pulmonary of the chickens. Injuries of the liver cells were reversible and the cell would return to its original stable state within a certain time limit (Kumar et al., 2013). Histopathological picture of chicken liver in P3, P4, P5, and P6 groups indicated liver damage, especially around the central port and venous regions. Toxocara spp. migrated to other tissues through the circulatory system. The route of migration through the bloodstream can subsequently cause hemorrhage and multifocal necrosis in the liver. Inflammatory cell findings and epithelial proliferation in the bile duct were also observed in all treatment groups. Infective larvae $T$. vitulorum can migrate through the portal vein and then enter the bile duct through enterohepatic circulation (Azizi et al., 2007).

Histopathological pattern of liver cells infected with L2 T. vitulorum experienced degeneration, swelling and was accompanied by necrosis, inflammation, and cholangitis. Toxocara spp. larvae secrete metabolic material that caused injury to liver cells. The products or secretions of infectious organisms are toxic to the metabolism or integrity of the cell membrane (Underwood, 1996). Degenerated liver cells experiencing cloudy swelling, microscopically present the granular cytoplasm and appeared to be foggy (Thomson, 1984). This change reveals that when water accumulates in the cytoplasm, cytoplasmic organelles also absorb water which causes swelling of the mitochondria and enlargement of the rough endoplasmic reticulum accompanied by the loss of ribosomes (Cotran et al., 1994).

Liver cell necrosis is characterized by three changes in the cell nucleus, including picnosis which means the cell nucleus appears round, dark, and smaller than the normal cell nucleus, karyorrhexis is splitting the cell nucleus into several parts, and karyolysis means when the cellular nucleus chromatin disappears and leaves holes in the cell (Thomson, 1984). L2 T. vitulorum infection in experimental animals caused cell necrosis and disabled the cells to stimulate changes so that eventually cell death occurred. This death is a result of releasing several enzymes, such as ATP-ase, phospholipase, protease, and endonuclease. Great or lethal lesions lead to irreversible cell damages because the cell cannot defend itself against injury.

Toxocara spp. larvae secrete metabolic material that increases the production of eosinophils as an immune reaction. Cellular activity and pressure of infection can stimulate microbicidal secretions, effectors, and inflammatory mediators. This pressure responds to cells to protect and fight unwanted conditions by minimizing damage and maintaining the integrity of the host tissue. Endoplasmic reticulum and mitochondrial tissue are key cellular organelles which give signals to cellular pressure (Abbas and Lichtman, 2003). Cholangitis is inflammation of the bile wall due to lumen infection. This situation can originate from any lesion that blocks the bile duct.

Therefore, L2 L. vitulorum can migrate to various organs and cause damage, hence some prevention can be done by health workers such as conducting training and counseling on the importance of cleanliness and environmental management. In addition, it is also necessary to provide support and regular assistance to farmers. This aims to minimize the spread of infection by reporting the cases to health workers. 


\section{CONCLUSION}

Infective larvae of (L2) Toxocara vitulorum administered orally could provide a change in the histopathological picture of broiler chicken's liver. Liver cell damages included cell degeneration, inflammatory cell infiltration, necrosis, and cholangitis. The P6 treatment group presented the most damage, compared to the other treatment groups, since the liver cells and other organs in chickens were exposed to toxic metabolic material released from the Toxocara vitulorum larvae during a longer period of time.

\section{REFERENCES}

Abbas AK, and Lichtman AH (2003). Cellular and molecular immunology. 5th ed. Philadelphia: Saunders, 32 (1): 65-66. DOI: https://doi.org/10.1002/bmb.2004.494032019997

Abbott NJ, Ronnback L, and Hansson E (2006). Astrocyte endothelial interactions at the blood brain barrier. Nature Reviews Neuroscience, $\quad 7(1)$ : $41-53 . \quad$ DOI: https://www.doi.org/10.1038/nrn1824

Azizi S, Oryan A, Sadjjadi SM, and Zibaei M (2007). Histopathologic changes and larval recovery of toxocara cati in experimentally infected chickens. Parasitology Research, 102(1): 47-52. DOI: https://www.doi.org/10.1007/s00436-007-0722-5

Cardillo N, Adriana R, Ribicich M, and Lopez CM (2008). Experimental infection with toxocara cati in BALB/c Mice, migratory behaviour and pathological changes. Zoonoses and Public Health, 56(4): 198205. DOI: https://www.doi.org/10.1111/j.1863-2378.2008.01182.x

Cotran RS, Kumar V, and Robbins SL (1994). Robbins' pathologic basis of disease. Philadelphia: W.B. Saunders, 12 (4): 377-377. DOI: https://www.doi.org/10.1002/dc.2840120422

Fenoy S, Ollero MD, Guillen JL, and Del AC (2001). Animal models in ocular toxocariasis. Journal of Helminthology, 75(2): 119-124. Available at: https://pubmed.ncbi.nlm.nih.gov/11520434/.

Hübner J, Uhlikova M, and Leissova M (2001). Diagnosis of the early phase of larval toxocariasis using IgG avidity. Epidemiologie Mikrobiologie and Imunologie, 50(2): 67-70. Available at: http://www.ncbi.nlm.nih.gov/pubmed/11329729

Khan AZ, Khan K, Zaman G, Ullah S, and Habibullah Q (2007). Prevalence of gastro-intestinal nematode parasites of economic importance in dairy buffaloes in peshawar, Sarhad Journal of Agriculture, 23 (3): 787-792 . Available at: https://www.aup.edu.pk/sj_pdf

Knodell RG, Ishak KG, and Black WC (2019). Formulation and application of a numerical scoring system for assessing histological activity in asymptomatic chronic active hepatitis. Hepatology, 1(5): 431-435. Available at: http://www.ncbi.nlm.nih.gov

Kumar V (2013). NKT-cell subsets: Promoters and protectors in inflammatory liver disease. Journal of Hepatology, 59(3): 618-620. doi: https://www.doi.org/10.1016/j.jhep.2013.02.032

Kusnoto (2005). Prevalensi toxocariasis pada kucing liar di surabaya melalui bedah saluran Pencernaan. Media Kedokt Hewan, 21(1): 711. Available at: http://journal.unair.ac.id/download-fullpapersMKH-21-1-02.pdf

Kusnoto S, Sosiawati S, Subekti S, Koesdarto S, and Puspitawati H (2007). Penuntun praktikum ilmu penyakit helminth veteriner. $2^{\text {nd }}$ ed. Surabaya: Departemen Pendidikan Nasional Universitas Airlangga,

Kusnoto, Subekti S, Ketut SI, and Soedarto (2011). Characterization and isolation of specific protein from Excretory-Secretory (ES) material of L2 dormant of toxocara cati for the diagnostic development of toxocariasis by ELISA Tehnique. Journal Unair, 13(1): 56-65. Available at: http://journal.unair.ac.id/download-fullpapersVol\%2013\%20No\%201\%20Jan\%202011-7.pdf

Levine ND (1995). Buku Pelajaran Parasitologi Veteriner. Yogyakarta: Gajah Mada University Press. Available at: http://library.um.ac.id/free-contents/index.php/buku/detail/bukupelajaran-parasitologi-veteriner-norman-d-levine-penerjemah-gatutashadi-editor-wardiarto-288.html

Oryan A, Sadjjadi SM, and Azizi S (2010). Longevity of toxocara cati larvae and pathology in tissues of experimentally infected chickens. Korean Journal of Parasitology, 48(1): 79. DOI: https://www.doi.org/10.3347/kjp.2010.48.1.79

Raza MA, Murtaza S, and Mazhar Ayaz M (2013). Toxocara vitulorum infestation and associated risk factors in cattle and buffalo at multan district Pakistan. Science International, 25(2): 291-294. Available at: http://www.sci-int.com/pdf/159243420018-291-294-Muhammad

Santos SVD, Santos FHY, Lescano SAZ, Santos DMD, Tiago EDS, Fonseca GR, Ribeiro MCSA, and Chieffi PP (2017). Migration pattern of Toxocara canis larvae in experimentally infected male and female Rattus norvegicus. Revista da Sociedade Brasileira de Medicina Tropical, 50(5): 698-700. DOI: https://www.doi.org/10.1590/0037-8682-0076-2017

Soulsby EJL, and Monnig HO (1982). Helminths, arthropods and protozoa of domesticated animals. 7th ed. London: Bailliere Tindall. Available at: https://www.worldcat.org/title/helminthsarthropods-and-protozoa-of-domesticated-animals/oclc/9189128

Starke WA, Machado RZ, Bechara GH, and Zocoller MC (1996). Skin hypersensitivity tests in buffaloes parasitized with Toxocara vitulorum. Veterinary Parasitology, 63(3-4): 283-290. Available at: http://www.ncbi.nlm.nih.gov/pubmed/8966994

Strube C, Heuer L, Janecek E, and Toxocara SPP (2013). Infections in paratenic hosts. Veterinary Parasitology, 193(4): 375-389. DOI: https://www.doi.org/10.1016/j.vetpar.2012.12.033

Taira K, Saitoh Y, and Kapel CMO (2011). Toxocara cati larvae persist and retain high infectivity in muscles of experimentally infected chickens. veterinary parasitology, 180(3-4): 287-291. DOI: https://www.doi.org/10.1016/j.vetpar.2011.03.020

Thomson RG (1984). General Veterinary Pathology. Available at: https://books.google.co.id/books?id=TeNnxZkddKMC\&q

Underwood JCE (1996). General and Systematic Pathology 2nd Edition. 2nd ed. London: Churchill Livingstone. Available at: https://www.amazon.com/General-Systematic-Pathology-J-CUnderwood/dp/0443052824

Yoshikawa M, Nishiofuku M, and Moriya K (2008). A familial case of visceral toxocariasis due to consumption of raw bovine liver. Parasitology Introduction, 57(4): 525-529. DOI: https://www.doi.org/10.1016/j.parint.2008.08.002 